Case Report

\title{
Meningoencephalitis: Rare manifestation of dengue haemorrhagic fever
}

\author{
S Puthra ${ }^{1}$, S Pirasath ${ }^{1}$, AGH Sugathapala ${ }^{1}$ \\ Sri Lankan Journal of Infectious Diseases 2020 Vol.10 (1):76-79 \\ DOI: http://dx.doi.org/10.4038/sljid.v10i1.8279
}

\begin{abstract}
Dengue is a common tropical disease occurring in Sri Lanka. Neurological manifestations due to dengue are very rare but can be caused by serotypes 2 and 3. Here, we present a patient with meningoencephalitis occurring as a manifestation of dengue haemorrhagic fever (DHF) in a young boy who presented with fever, constitutional symptoms and a seizure. Diagnosis was confirmed by NS1 positivity and the presence of dengue specific IgM in the CSF and characteristic electroencephalographic findings. He was treated according to the dengue national guidelines and had complete recovery without residual neurological deficits.
\end{abstract}

Keywords: Dengue haemorrhagic fever, meningoencephalitis, dengue NS1 antigen

\section{Introduction}

Dengue (DEN) is a mosquito born flavivirus infection with a clinical spectrum which ranges from asymptomatic infection to haemorrhagic fever and severe shock. Dengue is well known to be neurotropic in animal models as well as humans. Though human CNS infection is rare, considerable amount of evidence is increasingly reported to prove neural involvement of the DEN virus during the recent past. ${ }^{1,2}$ Neurological manifestations include dengue encephalopathy, direct neuropathic effects (dengue encephalitis, meningitis), immunemediated syndromes (acute disseminated encephalomyelitis, myelitis, Guillain-Barré syndrome, neuritis brachialis ), neuromuscular complications (hypokalaemic paralysis, transient benign muscle dysfunction, myositis), dengue-associated stroke and neuroophthalmic complications (maculopathy, retinal vasculopathy). ${ }^{3}$ However, dengue encephalitis is a rare entity. ${ }^{1}$ Here, we present a case of dengue meningoencephalitis in a young man who presented with generalized seizures on the second day of a febrile illness.

\section{Case History}

A 19-year-old previously healthy boy was found to have collapsed by the side of a road after a generalized tonic colonic fit and was brought to the accident service unit, Colombo South Teaching hospital, Colombo. He had high grade fever, arthralgia, myalgia and headache one day prior to this event.

${ }^{1}$ Colombo South Teaching Hospital, Kalubowila, Sri Lanka.

Address for correspondence: Dr Selladurai Pirasath, Colombo South Teaching Hospital, Sri Lanka Telephone: +0094775122995Ｅmail: selladuraipirasath81@gmail.com

https://orcid.org/0000-0002-4274-4919

Received 23 December 2019 and revised version accepted 8 April 2020

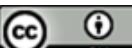

unrestricted use, distribution, and reproduction in any medium, provided the original author and source are credited.

SLJID • www. http://sljol.info/index.php/SLJID • Vol. 10, No. 1, April 2020 
An initial primary and secondary survey were performed, including a FAST (Focused Assessment with Sonography for Trauma) scan which excluded traumatic injuries. His admission GCS was 9/15. Subsequently, he was transferred to the medical causality unit. On further evaluation, he was febrile, restless with GCS of 12/15 and neck stiffness. His pulse rate was 92/minute and blood pressure 100/60 $\mathrm{mmHg}$.

Upon examination, he had no evidence of leakage. The dengue NS1 antigen was positive on day 3 of his illness. The EEG showed features suggestive of encephalitis. His initial full blood count showed a white cell count of $9000 / \mathrm{mm}^{3}$ with predominant neutrophils (52\%), 38\% lymphocytes and a thrombocyte count of $142000 / \mathrm{mm}^{3}$. On the $4^{\text {th }}$ day, his platelet count dropped to $74,000 / \mathrm{mm}^{3}$ with a raised packed cell volume (40\% to $\left.48 \%\right)$. His white cell count dropped to $3840 / \mathrm{mm}^{3}$ (neutrophils-45\%, lymphocytes-2\%). His liver enzymes were high (AST-78 IU/1, ALT-62 IU/l) but renal function tests were normal. Platelets dropped further to $42,000 / \mathrm{mm}^{3}$. His non-contrast CT brain was normal and his ultrasound scan showed the evidence of gall bladder oedema with mild free fluid.

His cerebrospinal fluid (CSF) analysis showed lymphocytosis of $25 \%$ and normal protein and sugar levels. CSF was negative for Japanese encephalitis virus and HSV IgM and IgG antibodies on day 4 of his illness. His serum HSV and EBV IgM and IgG antibodies and serum VDRL test and HIV antibodies by ELIZA method were also negative. His CSF culture showed no evidence of bacterial growth. His CSF for dengue IgM antibody was positive on day 4 with a positive serum dengue specific $\operatorname{IgM}$ and $\operatorname{IgG}$ antibody on day 10.

He was managed according to the national guidelines for dengue haemorrhagic fever published by the Ministry of Health, Sri Lanka. ${ }^{4}$ He improved clinically, and his platelet counts returned to normal limits on day 7 of his illness. He had complete recovery without residual neurological deficit at two weeks of his illness. The timeline of the patient's clinical course is shown below (Figure 1).

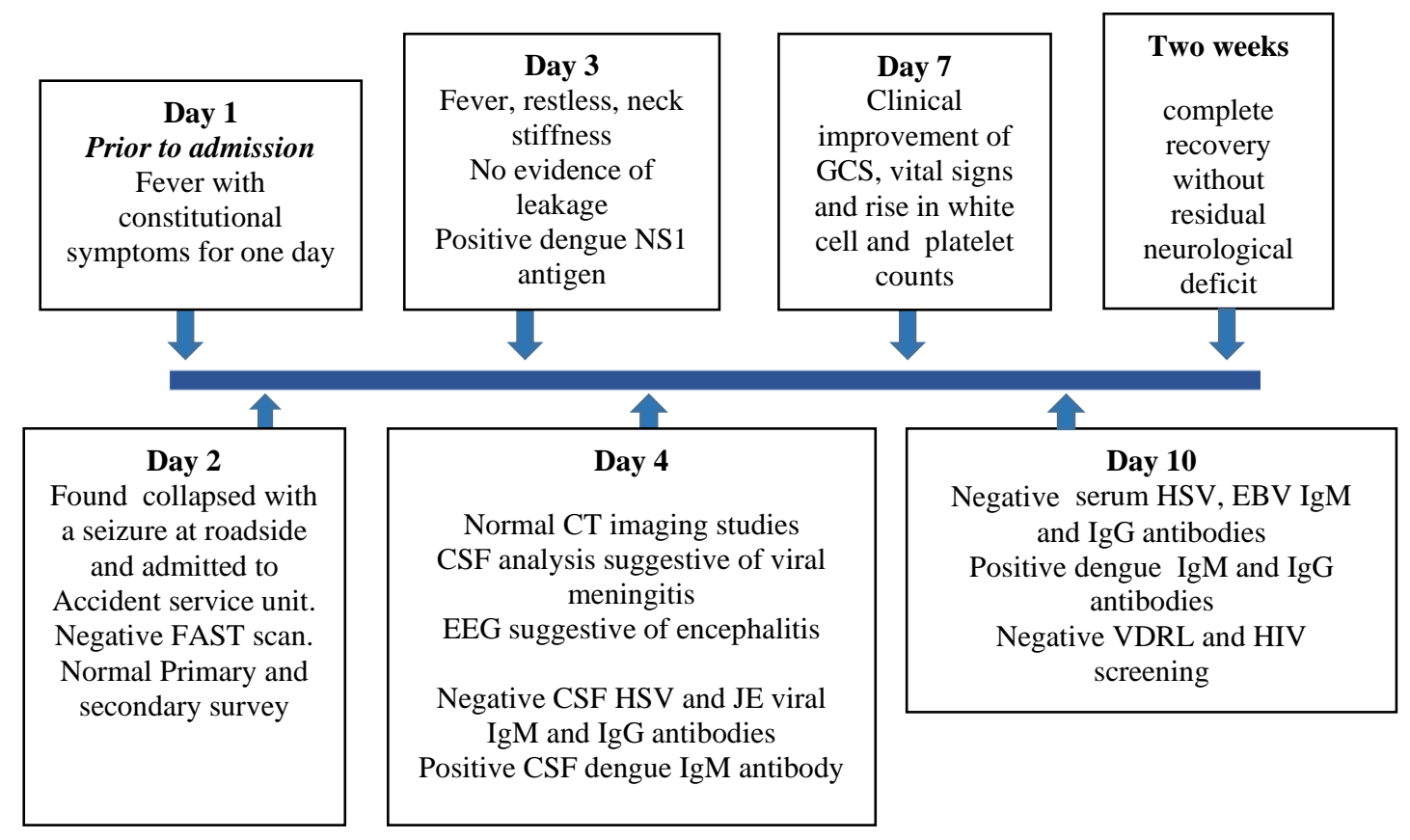

Figure 1: Timeline of illness 


\section{Discussion}

Dengue cases caused by all four DEN serotypes are now reported from almost all the districts in Sri Lanka and the infection is hyperendemic. ${ }^{5}$

Atypical and rare presentations of dengue haemorrhagic fever are being reported globally including Sri Lanka, with several cases reported of neurological manifestations. ${ }^{6-8}$ The World Health Organization (WHO) 2009 guidelines have recognized encephalopathy, encephalitis, and other unusual neurological involvements as manifestations of severe dengue. ${ }^{9}$ However, neurological manifestations are rare in dengue infection. ${ }^{9}$ The main symptoms of dengue encephalitis are headache, seizures and altered consciousness. The criteria for dengue encephalitis was defined as having the following features: i) fever, ii) acute signs of cerebral involvement, iii) presence of anti- dengue IgM antibodies or dengue genomic material in serum and/or CSF iv) exclusion of other viral encephalitis and encephalopathy. ${ }^{10}$ Typical symptoms of dengue fever like myalgias, rash and bleeding are seen in less than $50 \%$ of patients with encephalitis. ${ }^{6}$

Our patient had not developed the classical features of dengue and was haemodynamically stable during his illness. The main criteria for the diagnosis of dengue encephalitis in this patient was fever, acute signs of cerebral involvement with concurrent presence of anti-dengue IgM antibody and a positive serum NS1 with exclusion of other causes of viral encephalitis and encephalopathy. Based on subsequent evaluation, our patient fulfilled the diagnostic criteria of dengue encephalitis.

Early correct diagnosis and prompt timely management with a high index of suspicion has a definitive significant improvement in mortality and morbidity in patients with neurological complications due to dengue in clinical practice. Most importantly, physicians should consider dengue encephalitis as a differential diagnosis among patients who present fever and altered level of consciousness in dengue endemic areas like Sri Lanka.

Conflict of interest: Authors declare no conflict of interest

Ethics: Informed and written consent for publication was obtained from the patient

\section{References:}

1. Madi D, Achappa B, Ramapuramet JT et al., Dengue encephalitis-A rare manifestation of dengue fever. Asian Pac J Trop Biomed 2014; 4(Suppl 1): S70-S72 doi: https:// doi.org/10.12980/APJTB.4.2014C1006

2. Kapil Borawake. Dengue encephalitis Indian J Crit Care Med. 2011: 15(3):190-193. doi: 10.4103/0972-5229.84896

3. Murthy JM. Neurological complication of dengue infection. Neurol India 2010; 58:581-4 doi: https://doi.org/10.4103/0028-3886.68654

4. Ministry of Health, Sri Lanka. National guidelines. Guidelines on management of dengue fever \&. dengue haemorrhagic fever.

http://www.epid.gov.lk/web/images/pdf/Publication/guidelines_for_the_management_of_df_and_ dhf_in_adults.pdf

5. Prasad Liyanage, Joacim Rocklöv, Hasitha Tissera, et al., Evaluation of intensified dengue control measures with interrupted time series analysis in the Panadura Medical Officer of Health division in Sri Lanka: a case study and cost-effectiveness analysis. The Lancet Planetary Health 2019; 3: e211-18. doi: doi.org/10.1016/S2542-5196(19)30057-9

6. Weerasinghe WS and Arjuna Medagama. Dengue hemorrhagic fever presenting as encephalitis: a case report: J Med Case Report .2019; 13:278. doi.org/10.1186/s13256-019-2201-x

7. Withana, M., Rodrigo, C., Chang, T. et al., Dengue fever presenting with acute cerebellitis: $B M C$ Research Notes 2014; 7: Article 125. doi: https://doi.org/10.1186/1756-0500-7-125 
8. Misthaq ARM, Pirasath S, Sugathapala AGH. Isolated facial nerve palsy: Rare manifestation of dengue haemorrhagic fever - A case report. Sri Lankan J Infect Dis .2019; 9(1):95-9.

doi: http://dx.doi.org/10.4038/sljid.v9i1.8237

9. World Health Organization (WHO), Guidelines for diagnosis, treatment, prevention and control. 2009. A joint publication of the World Health Organization (WHO) and the Special Programme for Research and Training in Tropical Diseases (TDR),

http://www.who.int/tdr/publications/documents/dengue-diagnosis.pdf.

10. Soares C, Puccioni-Sohler M. Dengue encephalitis: Suggestion for case definition. J Neurol Sci 2011; 306:165. doi: https://doi.org/10.1016/j.jns.2011.04.010 